\title{
The freedom we mean: A causal independence account of creativity and academic freedom
}

\section{Maria Kronfeldner ${ }^{1}$ (D)}

Received: 5 January 2020 / Accepted: 20 April 2021 / Published online: 8 June 2021

(c) The Author(s) 2021

\begin{abstract}
Academic freedom has often been defended in a progressivist manner: without academic freedom, creativity would be in peril, and with it the advancement of knowledge, i.e. the epistemic progress in science. In this paper, I want to critically discuss the limits of such a progressivist defense of academic freedom, also known under the label 'argument from truth.' The critique is offered, however, with a constructive goal in mind, namely to offer an alternative account that connects creativity and academic freedom in a way that goes beyond mere reference to epistemic progress and involves reference to the freedom to think independently as the freedom we mean when we point to creativity and when we point to academic freedom. The resulting causal independence account is not only epistemologically stronger than a progressivist account, it also allows to counter the curbing of academic freedom in the name of progress. The latter becomes key, for instance, when authoritarian political regimes limit or negate academic freedom with reference to an epistemic progress suitably defined for that regime.
\end{abstract}

Keywords Creativity $\cdot$ Academic freedom · Originality $\cdot$ Spontaneity $\cdot$ Progress Argument from truth $\cdot$ Critical thinking $\cdot$ Democracy $\cdot$ Authoritarian regimes

\section{Introduction}

In this paper, I will analyze the connection between creativity and academic freedom in a way that diverges from the usual way of linking them via the concept of progress. I will discuss creativity and academic freedom as two kinds of freedom that both refer to a causal independence of the mind. That independence is the freedom

\footnotetext{
This article belongs to the Topical Collection: Creativity in Art, Science \& Mind Guest Editors: Adrian Currie, Anton Killin

Maria Kronfeldner

kronfeldnerm@ceu.edu

1 Professor of Philosophy, Central European University, Quellenstrasse 51, 1100 Vienna, Austria
} 
we mean when we defend creativity and when we defend academic freedom. It can be realized as critical thinking (the freedom to criticize) and can but does not have to connect to progress.

The paper contributes to, and fruitfully combines insights from, two fields that have so far been rather isolated: discussions about creativity in science and art, in which academic freedom is rarely at issue, and contemporary discussions about academic freedom, in which creativity is frequently mentioned but in passing only.

The presented causal independence account of creativity and academic freedom allows, as I will show, for a more secure foundation for academic freedom than what the standard account and the progressivist justification built on it can offer. It is more secure not just from a conceptual and epistemological point of view, but also from a political point of view, since it also allows to counter those cases in which academic freedom is politically jeopardized in the name of progress. This is important since authoritarian political regimes can limit or even completely negate academic freedom with reference to a suitably defined epistemic progress for that regime. Hence, the relationship between academic freedom and epistemic progress is a doubleedged one. In the name of progress, one can argue for academic freedom, but also against it. This is the challenge that progressivist justifications of academic freedom face and it is the challenge that this contribution aims to answer by focusing on how creativity and academic freedom relate independently of the concept of progress, i.e. by asking what kind of freedom we mean when we talk about creativity and when we talk about academic freedom.

The core negative claim in this paper is: if progressivist defenses of academic freedom leave out the freedom to criticize, then they are not sufficiently equipped to protect academic freedom against such attacks. The core positive claim is that we can decouple the defense of academic freedom from reference to progress since the freedom we mean when we talk about creativity or academic freedom is in both cases a specific kind of causal independence that can be realized in the freedom to criticize.

After showing in Sect. 1 what creativity is, and thereby how it connects to freedom in general, I will discuss in Sect. 2 how academic freedom - as standardly conceived - relates to creativity and progress. This will provide the bits needed to argue for the negative claim. Section 3 uses these results to argue for the positive claim, namely a separate, non-progressivist justification for academic freedom and, simultaneously, a suitably improved progressivist defense, built on an augmented concept of academic freedom, augmented with the core of creativity - independent thinking.

The resulting account and defense of academic freedom, linking it to causal independence, is in three senses better than the standard account of academic freedom and the progressivist defense built on it. First, the causal independence account does not rely on any progressivist thought. It is, second, epistemologically better grounded as it depicts the kind of freedom at issue more appropriately than the standard account of academic freedom, and thus describes the connection to creativity more appropriately. It is, third, a politically more robust account in the sense that it is a more effective argumentative barrier against those who challenge academic freedom in practice, e.g. in the name of a suitably defined progress, as part of which 
those that are deemed to criticize the respective kind of progress are silenced, or have to seek exile in order to survive as academics.

\subsection{Creativity requires partial independence from already existing knowledge}

\subsubsection{Standard accounts of creativity refer to originality and spontaneity}

Most accounts of creativity will assume that it requires originality, spontaneity and adequacy. ${ }^{1}$ To justify calling an act, process or product creative, it needs to be original (new), spontaneously produced (rather than routinely), and adequate (producing something of value, e.g. for a problem at hand). Since adequacy is a criterion that is also used for non-creative problem solutions, we are left with originality and spontaneity as the specific hallmarks of creativity. As the following will show, originality and spontaneity are also crucial to answer the following core question: what kinds of freedom are involved when scientists are creative? ${ }^{2}$

\subsubsection{Originality as a kind of freedom}

An act, process or product is original if something new is produced. The assumed contrast is that of learning from others. The difficult question has always been: 'new' in which sense? Is it creative, when somebody produces a new token of ceramic pots in a way that is typical in a certain population? Since it is creating something new (and of value, let's assume), creating a new token of a typical item of culture can indeed be regarded as creative. I call the kind of novelty involved anthropological novelty (see Kronfeldner, 2009). Creativity thus understood relates to a basic anthropological insight: humans are culture-producing animals. Yet, calling any cultureproducing behavior creative means using a very broad concept of creativity, one according to which every one of us will be creative most of the times.

When creativity in arts and sciences is at issue, as in this analysis, the implicitly assumed concept of creativity is, however, narrower. The novelty at issue is sometimes even restricted to historical novelty, to 'being the first one.' If so, then only those who did something for the very first time in history are taken to be creative. At issue is the kind of historical creativity that the 'hero books of science or art' utilize to tell their streamlined super(wo)men success stories. Yet, the utilized perspective results in a too narrow concept of creativity since what is most commonly regarded as creative in arts and sciences is not what is objectively new in history, but what is subjectively new: new in somebody's psychological history, i.e. unlearned. ${ }^{3}$

In my view, the most important point of distinguishing between historical and psychological novelty is the following: when psychological creativity is at issue, then it is not the objective existence of an original that takes away originality but

\footnotetext{
1 See for instance, the prominent accounts of Sternberg and Lubart (1999: 3) or Boden (2004: 1).

2 The following argumentation in this Sect. 1 is based on my previous research on creativity. For more details, see Kronfeldner (2009, 2011, 2018).

3 See also Boden (2004: 43-8) for the contrast between historical and psychological creativity.
} 
a specific causal relation to that original. What is at issue in attributing originality (and with it creativity) is whether one's mind was directly influenced by the respective original, i.e. whether one learned and thus copied the respective activity from an original or a person producing the original. Only if the origin of what one does is in oneself (rather than elsewhere) can originality be attributed to oneself. It follows that, in the context of arts and sciences, originality can be attributed if and only if psychological novelty can be attributed, i.e. when something is at the moment of creation new for the creative individual (rather than learned and reproduced). Certainly, in order to have one's own originality compromised by an original, there needs to be such an original, but the fact that there is an original is not sufficient for it to be compromising.

The primacy of psychological novelty for attributing originality rests on an important asymmetry, namely: while every historical novelty must have been a psychological novelty, the converse does not hold. Not every psychological novelty is a historical novelty. This asymmetry only comes into view when one connects the novelty criterion back to causal processes.

In sum, anthropological novelty would be too broad and historical novelty too narrow to capture what is usually meant by originality if creativity in arts and sciences is at issue. By comparing different kinds of novelties, we also saw that creativity requires a specific kind of freedom, namely a causal independence from what others have done in the past. ${ }^{4}$ Originality is a kind of freedom, a kind of freedom that is strictly necessary for creativity since it relates to what creativity is. It is a kind of freedom that we mean when we talk about creativity.

\subsubsection{Spontaneity as a similar kind of freedom}

Spontaneity refers to a similar kind of causal independence relation, just one within the creative individual. The contrast standardly used is routine method. If a person routinely produces something (a theory, a piece of art, etc.), then we usually do not call that act creative, even though we might call it productive. It is too dull a process to get the dignifying label 'creative'. 5 In the standard discourses on creativity in arts and sciences, creativity is attributed only if the creative person has no routine (i.e. mechanical) control over a production process, i.e. if there is insight, surprise and some unpredictability involved. This narrow usage of the concept of creativity stems from creativity's phenomenology. It points to what it is like to be creative. One finds that phenomenology in countless (self-)reports, e.g. in the famous story

\footnotetext{
${ }^{4}$ In philosophical analysis of creativity it is quite common to take creativity as a kind of freedom. Often, however, that happens with reference to metaphysical freedom, an idea that I criticized in Kronfeldner (2009) since the freedom referred to can be naturalized as an independence from certain causal influences (contrasted with metaphysical freedom, i.e. an independence from causal determination as such).

5 In contexts outside of arts and sciences, the label 'creative' is clearly more liberally applied to all kinds of activities that do not fit a pre-fixed description or constraints of sorts. E.g. when 'free'-lancers are called 'creative' this simply means that they are mostly left in a precarious situation, free to suffer the social ills that emancipatory political activities try to reduce by defending constraints on how 'freelancers' have to be treated in terms of social security and the like.
} 
of Archimedes shouting Eureka! at the moment when he suddenly realized how to solve the problem he was busy with: the problem of measuring the volume of an irregular solid form (such as a crown), in order to verify the material it is made of. He solved the problem, as the report goes, in the moment in which he lowered his very own irregular solid body into a Roman bathtube, noticing that the water spilled over the bathtube, and suddenly he got it: Eureka! Below, I will use the story of Kekulé, who (as his story goes) suddenly realized, after dreaming about snakes, how to solve the problem of the structure of the chemical compound benzene. But such Eureka experiences are not only to be found in often self-told stories; they also show up in the experiments of psychologists, who call it insight: the sudden spark of mental illumination, often following a stage of longer incubation.

Philosophically, this suddenness of insight can be conceptualized as a form of spontaneity. This is because one can raise one's arm by the power of one's will, but one cannot come up with an idea for a problem that demands a creative solution simply by the power of one's will. I assume that a freedom that operates without the command of the will is fittingly called 'spontaneous.'

Imagine you invented your very own technique of how to make ceramic pots; and now you make a numerically new pot using this technique. In such a moment, you are not performing a creative act in the narrow sense assumed here; you simply follow a routine, even if it is your very own routine. At that moment, you might be original (because the origin of that technique is in your mind rather than in someone else's mind), but you are not creative in the narrow sense. Spontaneity is missing. It is all too routine-like. This is why originality is not sufficient for creativity in the narrow sense assumed here. Spontaneity is necessary too.

Let me illustrate this point with the case of the German chemist Friedrich A. Kekule (1829-1896), who revolutionized chemistry with his solution for the puzzle of how to specify the molecular structure of the chemical compound benzene. Reporting on his discovery, he described how he fell asleep and had the following dream:

"I turned my chair to the fire and dozed [...] Again the atoms were gamboling before my eyes. This time the smaller groups kept modestly in the background. My mental eye, rendered more acute by repeated visions of this kind, could now distinguish larger structures, of manifold conformation; long rows, sometimes more closely fitted together; all twining and twisting in snake-like motion. But look! What was that? One of the snakes had seized hold of its own tail, and the form whirled mockingly before my eyes. As if by a flash of lightning I awoke." (Quoted after Findlay, 1968: 34-41; 39).

If the report is correct, then this dream was Kekulé's moment of insight that benzene forms a ring rather than a linear string, building with that the foundations of organic chemistry. ${ }^{6}$ There is evidence that Kekulé was skilled in visual imagination,

\footnotetext{
${ }^{6}$ Historians like Rudofsky and Wotiz (1988) have accumulated some evidence that the report is not correct. One should thus treat the case as an illustrative example, as a hypothetical paradigmatic example of what we mean when we talk about creativity.
} 
which might have been influenced by the fact that he studied architecture before he became a chemist. In addition, Kekule might have been subject to some visual impressions (e.g. visiting a zoo, visiting a dance performance) that influenced him when he visualized benzene in the way he reports. Yet, these causal influences (if they were operative, which we will never find out) do not make him less creative, i.e. they do not take away originality and spontaneity. How come? Because these influences have nothing to do with benzene molecules. If the story is correct, then his visual imagination was influenced by factors that come from outside of the context. Kekulés previous knowledge and his goal-orientedness to find a solution to the problem of the structure of benzene made it likely that he will find the solution, but his very own previously acquired knowledge and his goal-orientation were not sufficient for him to actually find the solution. He needed some inspiration - not outof-nothing metaphysically, but rather out-of-nothing relative to the problem-space he was dealing with. Such a relativized 'out-of-nothing' influence can account for the psychological originality and spontaneity involved. Given standard philosophical terminology, the causal influences that were involved in the emergence of his idea about benzene forming a ring are so-called coincidental influences. Coincidences account for surprise and practical unpredictability, an unpredictability not in any metaphysical sense, but an unpredictability for the creative subject as well as for other cognizers in the situation.

That creativity requires spontaneity in the specified sense does not mean that there is no goal-directedness involved. Creativity can happen without any goal (i.e. without a problem to solve in mind), as in cases of so-called true serendipity, and it can happen with a goal in mind. The latter can take place as part of pseudo-serendipity or as part of trial-and-error problem solving. ${ }^{7}$ In cases of true serendipity, one is not looking for a solution to a problem. One only recognizes something as a solution to a problem, i.e. one takes something to be a problem to be solved, at the moment one recognizes the solution to it. In cases of pseudo-serendipity, there is a perceived problem before the solution comes up, but there is no active search for the solution by producing trials. One simply comes across a solution while looking for it. If there is intentional production of trials, then it is trial-and-error problem solving. But even here the command of the will might not suffice to find the solution. Hence creativity is not opposed to goal-orientedness; it is just that goal-orientedness is neither necessarily part of the situation nor sufficient for finding a solution. The finding of the solution 'happens' to the problem solver. ${ }^{8}$

In sum, spontaneity amounts to the absence of foresight and the absence of control over the process of generating a solution. This means that creativity is opposed to routine production and technique (i.e. method). Viewed from an abstract point of view, spontaneity can be conceptualized as a causal independence from one's own previously acquired knowledge. That this is so is not just part of the phenomenology of creativity, it is part of what we mean when we use the concept of creativity in the

\footnotetext{
7 See Roberts (1989), who introduced these distinctions, and Kronfeldner (2011: 38-41) for details and examples.

${ }^{8}$ Compare Gaut (2009), for more on how goal-directedness and creativity connect.
} 
narrow sense in which it is used in arts and sciences. As with originality, it is thus conceptually necessary that creativity involves that specific kind of freedom.

\subsubsection{Summary: The freedoms we mean}

Both originality and spontaneity can be fulfilled in degrees and point at a specific kind of freedom, a partial causal independence from already existing knowledge - in others (originality) or in oneself (spontaneity). This means:

a) Originality amounts to a partial independence from the causal influence of an original, i.e. the already acquired knowledge in others.

b) Spontaneity amounts to a partial independence from the causal influence of previously acquired knowledge in oneself.

Given that the concept of creativity in arts and sciences is at issue, the resulting connection between freedom and creativity is the following: originality and spontaneity entail a partial causal independence from already existing knowledge, which is a kind of freedom that is necessary for creativity. It is a freedom we mean when we talk about creativity.

Yet, that kind of freedom is not equivalent to how academic freedom is standardly conceived. As I will show in Part 2, this is also why academic freedom as standardly conceived is not necessary for creativity. Part 3 then will use the concept of causal independence to augment the concept of academic freedom to point at how creativity and academic freedom actually relate, which shows that academic freedom can be defended quite irrespective of any progressivist commitments.

\section{Why academic freedom as standardly conceived is not necessary for creativity}

In the following, I will review important limitations that a strong and a weak version of the progressivist justification of academic freedom face if they are based on a concept of academic freedom as standardly conceived.

\subsection{Academic freedom as standardly conceived}

Academic freedom is an important freedom with a quite broad scope with respect to the liberties it guarantees practically. It includes not only the freedom to make specific scientific claims, but also the freedom of selecting topics and methods for research, the freedom to decide about the duration of research and the evaluation 
of the results, as well as the freedom to decide about their publication. ${ }^{9}$ In terms of philosophical conceptions of freedom, it can be portrayed as two-sided:

- Academic freedom entails negative freedom from infringement, with respect to all kinds of authorities (academic, religious, political, economic, etc.). This aspect is part of most accounts of academic freedom as well as part of most legislations.

- Sometimes it is added that academic freedom also entails positive freedoms, i.e. the presence of enabling conditions to exercise one's freedom, usually with respect to the duty of governments and universities to support the free research.

Hence, as standardly conceived, the term 'academic freedom' refers to the absence of disabling conditions and sometimes to the presence of enabling conditions. ${ }^{10}$

Depending on context, the bearers of 'academic freedom' are individual researchers (as in the context of discussion of this paper) or the community of researchers represented by respective collectives (e.g. science foundations that distribute public funding in a self-governed manner, independent of influences from governments or other political or economic interests). Sometimes, the discussion switches completely to the institutional level, i.e. to the autonomy of universities or similar institutions. $^{11}$

The taxonomy of traditional justifications for the thus conceived academic freedom is usually tripartite.

- Arguments from autonomy refer to personal autonomy of individuals as compromised if academic freedom is not respected.

- Arguments from democracy point at the function of academic institutions to foster open and democratic societies.

\footnotetext{
${ }^{9}$ Usually, these freedoms encompass matters of research and teaching. In this paper, the focus is on research. In addition, if the context of discussion relates to the legal status and protection of employees, then further freedoms are often added, e.g. the freedom to criticize superiors without retribution, the freedom to decide how to spend one's work time, etc. See Barendt (2010) on this more legal dimension.

10 That two-sidedness is directly mirrored in legislation, e.g. in how the granted freedom is legally interpreted. For instance, the German legislation (among the strongest in terms of protecting academic freedom) protects academic freedom as part of Germany's Basic Law (Grundgesetz) (Article 5, 3). Details are specified in the respective Higher Education Laws (Hochschulgesetze), e.g. in the 2006 Bavarian Higher Education Law (BayHSchG), in which the first sentence of Article 3 mentions the duty of the government and of universities to enable what is protected by the Basic law, and the second sentence specifies the scope of that protection (basically as portrayed above). For details on these issues, see Barendt (2010).

11 Apart from these general points, not much agreement exists on the concept of academic freedom (what it means, what its scope is), which is mirrored in issues and disagreements about how to measure it. See, for instance, Fish (2014), on five different accounts of what academic freedom entails in practice. Differences in the accounts that Fish presents depend mostly on how to interpret the function of 'academics' in society and on how science and politics should connect. See Matei and Iwinska (2018) for review of how academic freedom is measured in the European Higher Education Area, in order to monitor it in practice. They not only refer to the evidence about diversity of meanings between different cultural contexts, but also to diverging paths of academic freedom at the individual level on the one hand, and institutional autonomy (the freedom of academic institutions such as universities) on the other hand.
} 
- Arguments from truth refer to the claim that without academic freedom there will be no progress in matters of truth.

The labels used for these justifications in the growing literature on academic freedom differ, and some authors mention only a subset of them. ${ }^{12}$ One representative example has to suffice, given the space available here. Dworkin (1998), for instance, discusses only the last two, but can be interpreted to use a combination of the first two under the label "ethical individualism," the principle that, according to him, grounds the overall justification of academic freedom. Finally, for the aims of this paper, it is also important to note that the first two are often taken to be ethical or political, while the third is taken to be epistemological.

The rest of Sect. 2 will discuss the third, the argument from truth (henceforth: progressivist justification), by revisiting specific claims made about creativity and academic freedom (taken to lead to epistemic progress). To do so, I will distinguish between a strong and a weak version of the progressivist justification and show the limits of both. Section 3 will then open a way to reconnect the ethical and political side with the epistemological side in a way that solves the issues that arise from the limitations of the claims reviewed in Sect. 2, resulting in an augmented concept of academic freedom, an outlook for a new nonprogressivist justification of it, and even an improved progressivist justification.

\subsection{A strong and a weak version of the progressivist justification}

Progressivist justifications of academic freedom have been used in different versions ever since J. S. Mill raised the issue of freedom of thought in his On Liberty (1859), and even before - for instance, in John Milton's Areopagitica (1644). In contemporary literature, they are mounted on the assumption that it is the function of academic research (and the institutions in which it happens) to advance knowledge, i.e. to produce epistemic progress. ${ }^{13}$

The progressivist justification exists in two versions, a strong and a weak one. Michael Polanyi (1951) can be interpreted as having defended a strong version of it, and he does so with explicit reference to creativity, which is why I have chosen him as an example to illustrate the progressivist point of view. Polanyi claimed that science combines two seemingly contradictory principles: the ideal scholar is

\footnotetext{
12 Compare Andreescu (2009), whose terminology I more or less follow, with Wilholt (2012), who uses the same line-up but different labels. Other divides are certainly possible. Barendt (2010: 53-63), for instance, distinguishes between consequentialist and deontological versions of the third, the argument from truth. Only his consequentialist version of the argument from truth is at issue here; his deontological versions relate the search for truth to the argument from autonomy or democracy. These three references can also serve as entry points to the overall body of literature on the topic, with Andreescu connecting things to higher education studies, Wilholt to philosophy of science, and Barendt to legal studies. 13 See Post (2006) on how this relates to the history of how institutions of higher education in the US have only gradually incorporated this function. See Barendt (2010) on how this relates to other contexts, in particular Great Britain and Germany, where not just the legal context differed and still differs but also the history of higher education and how it connects to research and its function to advance knowledge.
} 
simultaneously creative and disciplined. That means, the ideal scholar enjoys full creative freedom and is simultaneously fully "dedicated to the service of a transcendent reality" (ibid.: 584), and in that sense disciplined, devoted to that reality and the truths about it. ${ }^{14}$ Given these two simultaneous orientations of the ideal scholar and given the social structure of academic research (the cooperation between scholars), progress regarding truth can happen and regularly does happen, but only if academic freedom is granted. In his account, the "efforts" of scholars.

"will be efficiently co-ordinated if only each is left to follow his own inclinations. It is claimed in fact that there is no other efficient way of organizing the team, and that any attempt to coordinate their efforts by directives of a superior authority would inevitably destroy the effectiveness of their cooperation." (Polanyi, 1951: 34, emph. added).

The effectiveness he means is progress regarding truth (epistemic progress). From that it follows that reality is the only authority scholars should take into account, and that "[a] ny intervention on the part of an outside authority could only destroy their contact with the aims which they are pledged to pursue" (ibid.: 40), namely aims that relate to epistemic progress. He claims that in the short run such outside interventions lead to "distortion" and in the long run to "more or less complete destruction of the tradition of science" (ibid.: 57).

Claiming that without academic freedom epistemic progress would be destroyed, combined with the claim that academic freedom is the only efficient way to organize science, means that academic freedom is taken as necessary for creativity, innovation and thus progress in science. That is quite a strong claim.

The weaker version of combining academic freedom and epistemic progress (and thus a weaker interpretation of Polanyi) would be the claim that without academic freedom, epistemic progress would be much harder to achieve, a claim that is more akin to Mill's original version (as I will show below). The claim would then be that the long-term progress towards more and more truths is not destroyed but hindered if academic freedom is absent; the resulting system of science would be less efficient.

It would be a matter of in-depth textual examination to clarify whether Polanyi really meant to defend a strong version, which can be criticized rather easily (as I will show below). This interpretative historical question is beyond the scope of this article. All that I want to claim is that Polanyi can be interpreted in that way and as such he represents a standard way of putting things; so standard in fact that it is often rather briefly put. One example has to suffice: Barendt (2010: 57), for instance, summarizes the progressivist justification as asserting "that academic freedom is necessary to enable university professors and teachers to advance human knowledge through conducting research, publishing their findings and communicating them

\footnotetext{
${ }_{14}$ For instrumentalists in philosophy of science (and I count myself as leaning towards instrumentalism) this is clearly the wrong start, but for the purposes of this paper it does not matter whether realism or instrumentalism is the assumed framework for defending a progressivist justification for academic freedom.
} 
to students in lectures and seminars." ${ }^{15}$ Epistemic progress is here defined as the advancement of knowledge, i.e. the discovery of new truths.

I will not indulge in any further textual interpretation, neither for classic accounts like Polanyi, nor for contemporary accounts that involve necessity claims. I will rather follow a systematic route. As part of that, I will use the strong version as a wetting stone (since it is so easily refuted, a 'straw man' as we sometimes say), but with a specific constructive intention in mind: to guide the reader through, from the strong version to the weaker version, in order to clarify what can be defended in each. As we will see, it is not much, but reviewing it is vital to find the common core between creativity and academic freedom, which will be the topic of Sect. 3.

\subsection{Against the strong version of the progressivist justification}

In the strong version of the progressivist justification, academic freedom is portrayed as necessary for creativity, innovation and progress: if academic freedom is not guaranteed, new truths will not be discovered, i.e. no creativity will happen. As mentioned, this is clearly too strong. I will show this not by going into the details of the history of the progressivist justification for academic freedom, ${ }^{16}$ but on the basis of a case-based refutation. At issue, then, is what follows from this refutation with respect to how creativity and academic freedom relate. I will analyze the latter by adding insights from creativity research.

The necessity claim in the strong version of the progressivist justification is easily proven wrong, simply by the existence of innovations that resulted from constraints and guidance, if not pressure. There is an abundance of government-, military-, or industry-funded cases (take the internet, for instance, which originated from a military context) that led to epistemic progress even though academic freedom was limited if not absent. If choice of topic is influenced by governments via providing more funds for certain topics than for others, academic freedom is already a bit limited, but not absent as long the positions of the researchers are not at peril should the researchers ignore that 'nudge'. Academic freedom is absent if topic choice, research methods, duration of the research, evaluation and publication of results is to a large extent or completely determined from outside, as it is often (not always) the case in military contexts and contemporary industry contexts, as part of which the research is 'directed'. ${ }^{17}$ As Guston (2000) reports, looking back at different systems

\footnotetext{
15 Further quotes could be added. Barendt (2010: 51), for instance, also reports that "traditionally" the "distinctive task" of universities has been specified as "the methodological discovery and teaching of truths about serious and important things. Professors, lecturers and researchers enable universities to discharge these special responsibilities, it is argued, only if they enjoy the academic freedom to discover and transmit knowledge of the truths of their discipline." (emph. added).

16 For the history of defending a progressivist justification, before and after Mill, see Wilholt (2012).

17 It is certainly not the case that industry-, military- and government-contexts automatically prevent academic freedom due to their respective goal-orientedness. It depends on which model of research productivity is used. Directly after the Second World War, the so-called 'linear model' of research funding dominated. Bush's (1945) Science: The Endless Frontier counts as the landmark of that model. It assumed that if and only if you grant positive and negative academic freedom, innovation will result. It utilizes the same necessity relation between academic freedom and progress that we discussed above,
} 
of research funding in major areas since the Second World War (e.g. in the United States of America, Great Britain, Japan, Germany), some granted freedom was in vain since it was not sufficient for the respective progress and sometimes pressure and constraints were quite productive 'mothers of invention.'

On the basis of that history, it seems to be by now common sense in science policy that creativity does not always happen even if freedom is granted (academic freedom not being sufficient), and if creativity happens it can happen without academic freedom (academic freedom not being necessary). If so, if academic freedom is neither necessary nor sufficient for creativity, what, then, is the relationship between creativity and academic freedom?

Before I can provide an answer in Sect. 3, it is worthwhile to briefly deepen our account of this result by analyzing why academic freedom fails to be necessary for creativity. The above-mentioned existence claims, after all, do not entail a reply to this question. Some counterfactual scenarios combined with insights from the psychology of creativity can help in that respect. Recall Kekulé's story. Was it necessary that he had academic freedom for his discovery that benzene forms a ring, opposing thereby the 'dogma' (conventional truth of the time) that molecules of that kind can only form linear strings? The following will illustrate that it was not, neither with respect to positive freedom nor with respect to negative freedom.

Imagine a counterfactual scenario in which Kekulé, at the time of his discovery, was a young scientist striving for a secure position. An authority - be it academic, religious, political or economic - told him that he would not get a permanent position or any further funds if he does not find a solution to the important chemical problem about the structure of benzene. That 'pressure' and negation of positive academic freedom would very likely have had effects, including effects on Kekulé's creativity. Yet, these effects could have been either negative or positive. As mentioned, sometimes 'necessity' in the sense of a pressure of having to find a solution is the 'mother of invention', nudging creativity on; at other times, pressure and constraints will stifle creativity. It all depends on the details. Jon Elster (2000) tried to account for this two-sidedness of the relationship between pressure, constraints and creativity and claimed that there is a U-shaped relation: too much pressure (left side of the $U$ ) harms creativity, some pressure is productive (bottom of the $U$ ), while too much freedom is detrimental (right side of the U). This two-sidedness of the effects of pressure on the one hand and freedom on the other hand confirms the abovementioned consensus: positive academic freedom (as conventionally defined) is not necessary for creativity; it can hamper it too if it is too much. What remains is neither necessity, nor a positive correlation that has 'more creativity, if more positive freedom'. All that remains, is a U-shaped relation. The rest - the right amount and

Footnote 17 (continued)

which leads (because of the simultaneous sufficiency claim) to a linear path from academic freedom to useful innovations-from free, non-instrumental, basic science to targeted, instrumental, applied innovations for the respective context (see Ziman 2003, for details). There is now a broad consensus that the linear model is wrong. Varma (1995) therefore contrasts the linear "autonomous" model that dominated in the USA directly after the Second World War, with what she calls "linkage" model, as part of which researchers are 'on a leash', tightly controlled. According to her, since around the 1980s the linkage model took over the USA industry's research funding. 
the right kind of support and pressure that is productive in a specific setting - is in the legendary 'devil's details.'

But what about creativity and negative academic freedom? It seems that this is the easier case for defending that academic freedom is necessary for creativity. Let's imagine this time that an authority - again, be it academic, religious, political, or economic - told Kekulé that he would end up in dire straits (e.g. in prison) if he defends anything else than the received view that organic molecules form a linear string. The crucial point is that more severe 'pressure' and 'interference' (related not just to the absence of enabling conditions but the presence of disabling conditions) would still not have necessarily taken away his creativity since creativity is first and foremost cognitive. He could still have come up with the idea. And maybe he would have been even more likely to arrive at his revolutionary idea, given the pressure. He might have thought: 'If the authorities are so afraid of the dogma being criticized, maybe there is something to gain from questioning it; maybe that rule of linearity is the stumbling block of why I cannot find a solution.' In psychological creativity research, such a sudden questioning of a foundational background assumption that frames the search for a solution is called Gestalt switch. It is taken to explain at least part of the spontaneity in creative cognition. ${ }^{18}$ Certainly, the mentioned pressure can also stifle creativity, e.g. by creating so much fear that serious creative thought is indeed becoming impossible. In addition, it can easily prevent (if the threat is successful) that creativity leads to epistemic progress. After all, creativity is clearly not sufficient for epistemic progress. For the latter, there needs to be uptake and for that ideas need to circulate. The circulation of new ideas can very efficiently be stifled if there is no academic freedom. Censorship has indeed been used in history extensively by diverse authorities. But censorship refers to the circulation of ideas, not the origination of ideas. In a censorship context, you can have the ideas; it is just that you are not allowed to spread them.

To sum up: at the psychological level of creativity, it appears that new truths can emerge in individual minds, even if there is no positive and no negative academic freedom. It is not even clear that there is a tendency toward more creativity in situations of full freedom since too much freedom can hinder creativity, as I explained above. Thus, academic freedom is neither necessary for creativity as a cognitive phenomenon nor always productive. However, as I have shown in Sect. 1, originality and spontaneity are necessary for creativity. But - and here's the rub - these kinds of freedom are not the same as academic freedom, at least as academic freedom is standardly defined, namely as discussed in this Section. This will be important for Sect. 3, where I will try to superimpose these different kinds of freedom to bring to the fore their common core. But before we can go there, the weaker version of the progressivist justification needs to be addressed since that is what critics will point to in reply to what I said so far on the relationship between constraints and creativity.

\footnotetext{
18 See Öllinger et al. (2013), for instance, for a contemporary defense of the tradition going back to the Gestalt psychologist's account of creativity.
} 


\subsection{Problems of the weak version of the progressivist justification for academic freedom}

There is one option left to secure a positive correlation, even if the above is taken for granted. At a populational and thus historical level (i.e. all individual researchers or groups of them taken together), academic freedom might still be positively correlated with creativity, giving credence to the claim that the absence of academic freedom can hinder scientific progress, making science less efficient. There seems to be a broad consensus about that claim being true, at least as a prima-facie hypothesis. Leiter (2018: 33), for instance, writes that the "central rationale for academic freedom in the Western universities has always been that such freedom makes discovery of the truth more likely," deriving this claim, as so many, from the authority of J. S. Mill's version of the progressivist justification of academic freedom. Yet, the situation is less promising if one looks at the evidence that could justify the confidence that this classic claim is true.

To validate it, one would have to go beyond thought experiments, psychological insights, or anecdotal evidence from history (kinds of evidence or reasons that I myself used above). Yet, when people refer to a population-level correlation of academic freedom and epistemic progress, as Kitcher (2004) already mentioned, they do so often "from the armchair," with "a few bits of anecdotal evidence" only, "having read a book on Lysenkoism and a biography of Einstein." As he continues, "[i]n fact, little is known in any systematic way about the responsiveness of scientific research to social directives." (Kitcher, 2004: 56; 2011: 119) ${ }^{19}$ After all, the method of cases (used for generating counterexamples, as I have done above) works only if you want to falsify a specific claim; for inductive inferences to support a statistical correlation at a populational level, evidence from a few cases, and the existence claims resulting from them, simply do not suffice.

The problem is that it is rather unlikely that one can go beyond existence claims since it is hard to imagine how to study that correlation empirically, with a convincing solution to sampling of the cases, replication, etc. After all, everyone can make her or his own garden-variety list of innovations that relied on autonomous science and contrast it with another list that relied on some kind of pressure.

To illustrate: Basalla (1988), for instance, defended in his famous evolutionary account of technological change that need or pressure does not always drive cultural change. To infer, however, that innovation is not often oriented at needs, as Mesoudi (2008: 249) seems to interpret Basalla, is overstating the case. 'Often' is a suspiciously vague qualifier, in this case thrown in for good measure. To be convincing, it needs backing-up by systematic empirical evidence, quantifying the 'often' with a well-justified selection of cases.

It follows that it is hard to say, in general, what kind of innovation is more frequent and under which conditions exactly. We might be able to historically or counterfactually study specific settings, for instance, how innovative the contemporary US Science and Higher Education Area is compared to the contemporary European

19 See Wilholt (2012: 169) for a similar point. 
equivalent, which is what most empirical research in innovation studies does. However, generalization to an overall correlation of academic freedom with innovativeness will be beyond the reach of such studies. This is because in addition to issues about sampling, it is still the case that measuring the two core variables - academic freedom on the one hand, and the success of science (epistemic progress) on the other hand - is quite a contested affair, and highly context-dependent, which makes it unlikely that meta-studies are solving the problem.

As mentioned, sufficient systematic evidence seems to be unavailable for the case at issue; neither the psychologists in their labs, nor the economists, sociologists or historians in their field of actual history of science and technology can provide it in the form necessary. I conclude that the evidence that is and can realistically be available only allows for the following: first, existence claims (i.e. innovation exists with and without academic freedom being fully granted); second, empirically backed-up claims about some rough patterns (e.g. Elster's U-shaped relation between pressure and creativity); third, some contextual insights (e.g. regarding differences between the US area directly after the Second World War and since the 1980s).

Before I summarize, a note on Mill needs to be added: Mill's famous chapter on The Liberty of Thought and Discussion in On Liberty (1859) can be interpreted to provide a defense of the population level correlation between progress, creativity and academic freedom as standardly conceived. His argument is interesting, historically as well as philosophically, but this paper cannot do full justice to it. This is so since the argument Mill provides is not based on a well-selected set of cases that grounds an empirical confirmation of a generalization. It rather refers to an invisiblehand mechanism of selection, akin to natural selection. The claim is that truth (like a biological adaptation) will automatically win against falsity in the long run, but only if freedom of thought and expression is provided. This claim is based on the assumption that there is an asymmetry in the probabilities in which truths and falsities reappear, which, I think, is unfortunately very often simply wrong. Yet, to probe that assumption in detail (why it is so often wrong; and, with that, why the 'free market of ideas' so often fails to reliably produce epistemic prosperity) has to wait for another occasion.

\subsection{Summary of what's the problem with the progressivist justification}

Since basic assumptions need to be probed further and since a lot of historical, social and psychological evidence needs to be accumulated to really confirm that academic freedom is generally positively correlated with creativity, and since that kind of evidence is hard to get, I conclude the following: connecting academic freedom and creativity the way the weak version of the progressivist justification does is not necessarily wrong but it is not a very secure foundation for defending academic freedom.

Section 3 will offer an account of academic freedom that is more secure since

it directly connects academic freedom with the kinds of freedom that are indeed necessary for creativity - namely, originality and spontaneity. That way it will also be possible to suggest an independent, non-progressivist epistemic defense of 
academic freedom and, simultaneously, to suggest improvements for the progressivist justification.

\section{The causal independence account: A richer way to conceptualize academic freedom}

The guiding idea in the following is that the concept of academic freedom as standardly conceived is under-specified. It needs to be augmented - with a reference to causal independence as the freedom we mean when we talk about creativity and when we talk about academic freedom. This will provide the looked-after close connection between creativity and academic freedom. A progressivist justification can profit from this connection, but the connection also reorients the focus to something else than epistemic progress. As a result, a non-progressivist epistemic defense of academic freedom comes into view.

\subsection{Creativity and thinking independently}

Recall our second counterfactual Kekulé story, in which an authority told Kekulé that he would be put in prison if he defends anything else than the 'dogma' (the received wisdom). Such pressure is not necessarily taking away creativity, or so I argued, but it can take it away. How does the situation look like if creativity is in fact taken away? There is no creativity, and if there is no creativity, then there is no originality and/or no spontaneity. This follows from Sect. 1. The kind of freedom that Kekule would thus have lacked in that counterfactual situation is often called the freedom to think differently. What is disabled is a critical stance toward the received wisdom.

I assume in the following that critical thinking is one realization of thinking independently. It is thus one realization of the kind of independence that we have seen to be necessary for creativity. It follows that critical thinking is necessary for creativity, at least in all those situations where there is relevant previously acquired knowledge. Thinking creatively is thinking differently, which is thinking critically. This is conceptually true as long as being critical means what I just assumed: thinking independently. A mind that is truly critical is not just skeptical about something (since that's rather easy); it is an independently thinking mind that is able to think things through in an independent manner in order to contribute to the production and preservation of knowledge. Thus, if the absence of academic freedom takes away creativity, then it does so since it takes away critical thinking. This, and not the potential consequences (epistemic progress), is the core connection between academic freedom and creativity.

\subsection{Augmenting the concept of academic freedom}

With this we can also augment the concept of academic freedom, as standardly conceived (i.e. as presented in Sect. 2). Academic freedom consists in a specific kind of 
intellectual causal independence. If I think critically, I have used, as a matter of fact, my ability and right to do so, whatever the negative and positive enabling conditions of academic freedom. This means that a fully developed concept of academic freedom should refer to the causal independence of the mind explicitly, as the kind of freedom we mean when we talk about academic freedom. The causal independence of the mind is what needs to be protected with the negative and positive enabling conditions entailed in the standard account presented in Sect. 2.1.

It is very important to note, though, that critical thinking is just one realization of the freedom we mean when we talk about creativity and academic freedom. Even though academic freedom needs to allow for critical thinking, academic freedom is, after all, not the same as creativity or critical thinking. Academic freedom needs to be exercised with respect to old truths as well. ${ }^{20}$ Not all significant truths are new ones; sometimes protecting the already achieved wisdom from disappearing is equally (if not more) important than epistemic progress.

Take well-established truths that concern historical events. Is it a matter of defending academic freedom if we aim to protect the knowledge reached about the Holocaust, in the face of strategic Holocaust denials? Yes, it is. The causal independence of the mind that is necessary for creativity is realized in such a case as an independence from strategic influences that try to lure society into the neglect of important truths (and for obvious political reasons). These influences can disable the collaborative knowledge production and preservation that we take academic freedom to protect. Hence, protecting these well-known, far from creative historical truths means using and defending academic freedom (protecting it from political influences), even if it can limit the free speech of individuals (in our case, Holocaust deniers).

Not just epistemic progress is at risk when academic freedom is at issue. If political and other strategies interfere too much with academic affairs, the very institution of academic research is at peril, not just the epistemic progress it produces, as Polanyi already mentioned. Knowledge - whether old or new - is valuable and vulnerable, and as knowledge it needs protecting. Academic researchers inherit the respective protection from the knowledge to be protected, but only in so far as they are in the serious and independent business of academic knowledge production and preservation.

It follows that if we augment the concept of academic freedom with an explicit reference to the causal independence of the mind, we have utilized that creativity (and with it progress) and academic freedom require at its core the same kind of freedom. Since that is a tighter connection than what the weak progressivist correlation discussed in Sect. 2.5 can offer, I take this augmented account to better fit the

${ }_{20}$ Thanks to an anonymous referee for reminding me about this point. 
frequent intuition that there is a tight connection between creativity and academic freedom.

How to spell out that augmentation in detail has to wait for another occasion. It is clear that the kind of causal independence that I specified in this contribution relates to what is often called objectivity. But bringing in the details on that core epistemological concept would lead us too far away, given that the focus here is on the connection between creativity and academic freedom. ${ }^{21}$ What needs to be done in the future is to analyze how the kind of independence of the mind that we call academic freedom relates to the kind of independence of the mind that is often called objectivity. To understand that is important, not only to spell out the causal independence account presented here, but also to show why protecting academic freedom means to criticize (rather than to protect) strategic denials of empirically well-grounded truths. It is one of the absurdities of our time that academic freedom is increasingly often (ab)used by those who strategically deny well-confirmed scientific knowledge, for often quite evident political reasons (e.g. take as a historically well-documented case climate skepticism and the political and economic interests that fuel it). ${ }^{22}$ Using and defending academic freedom can mean protecting important established truths from disappearance if wrongfully attacked, as it can mean protecting the production of new truths. The function of academia is not only to disseminate and to advance knowledge; academia is, in its utmost core, the powerhouse of knowledge protection, committed strictly and exclusively to academic standards, restricted only by general ethical and political principles (e.g. limits on experimentation with humans, orientation at the common good, a duty to further human rights).

\subsection{What follows: A non-progressivist defense and a better progressivist defense}

Given what I said so far, two vistas are open:

a) A non-progressivist epistemic defense of academic freedom: Given that old truths also deserve protection, the core value of academic freedom is independent of any considerations of progress but intimately connected with creativity since it refers to the same kind of causal independence of the mind. In other words, the causal independence account presented here opens up a way to an epistemic argument for academic freedom that is completely independent of considerations about progress since it does not only look at novelty and progress, but also at the "here and now.' Such a non-progressivist justification for academic freedom can more easily accommodate the view that old truths need to be protected as well. The project of elucidating such a non-progressivist epistemic defense of academic freedom, however, goes beyond the scope of this contribution. Here, my goal is to depict the connection between creativity and academic freedom independently of progressivist thoughts. The core point in that respect is that the notion of an

\footnotetext{
21 See Reutlinger (2021) instead, for an account of objectivity that also uses the concept of independence.

22 See Oreskes and Conway (2010)'s very accessible summary of the case.
} 
independent mind is the common core of the concept of creativity and a suitably augmented concept of academic freedom.

b) A limited but defensible version of the progressivist justification. This common core can also be used to improve the progressivist justification. After all, we now have a necessary condition for creative thinking in place, independent critical thinking, and with that a necessary condition for the innovation and progress that follows from it, resulting in a revised progressivist justification for academic freedom. As mentioned, I am certainly not the first one who connects critical thinking and academic freedom. Dworkin (1998), Andreescu (2009) or Wilholt (2012), for instance, also mention critical thinking with respect to academic freedom, but they fail to discuss its epistemological importance in a way that simultaneously allows to see its conceptual connection to creativity. In addition, they mainly discuss critical thinking with respect to its ethical or political importance (i.e. for the argument from autonomy or the argument from democracy). Critical thinking's epistemic relevance shows up with respect to Mill's claims about the above-mentioned asymmetry or his and also recent claims about the related value of diversity of thought, as in Wilholt (2012). But the connection to creativity is nonetheless ignored since the focus is on the consequences of diversity, not on how it originates (not surprising, given that Mill was a consequentialist). Yet, the independence account of creativity and academic freedom presented here allows bringing into view the wider epistemological relevance of independent thinking. After all, creativity explains the origin of diverse ideas, not just the consequence of diversity in ideas. In addition, bringing critical thinking into the progressivist picture also shows that the epistemological side of academic freedom is deeply connected with its political side, since independent thinking is important for both: progress regarding truth and progress in democracy.

Last but far from least, independent thinking is what non-democratic authorities are unisono afraid of, when they attack academic freedom in order to abuse institutions of knowledge production and preservation (research and education) in order to achieve their kind of epistemic progress. This, finally, allows me to clarify why all of the above matters not just epistemologically but also politically.

\subsection{Why that all matters politically}

Progress is not easy to define, and it can be the handmaiden of all kinds of political regimes - authoritarian regimes, in particular. For instance, since roughly 2017, the Hungarian government launched several attacks against academic freedom. When it declared gender studies to be an illegal degree program in Hungarian higher education (in August 2018), a progressivist justification was put to use (even though not always explicitly). Humanities, arts and sciences need to function in an efficient manner, meeting the "real social and labor market needs," was the assumption, as the journalist Serduilt (2018) reports. With respect to the "labor market needs" the Hungarian government stated that gender studies can only produce unemployment; with respect to the alleged "real social" needs it simply pointed to its conservative values and outlook for the Hungarian people. 
According to the government, Hungarian research and education should help furthering the Hungarian people's wellbeing, and gender studies, they claimed, fails to do so.

Epistemic progress for the Hungarian government, it seems, is progress regarding truths about heteronormative families as the nucleus of society. After all, the Hungarian government created a new MA program in family studies to replace gender studies, as the journalist Szikra (2018) reports. Truths about the diversity and contingency of gender roles, sex or sexuality seem to be regarded as irrelevant or even harmful. Already in 2017, the Secretary of State of the Ministry of Human Resources, Bence Rétvári, was very explicit about the Hungarian government's negative attitude toward gender studies. For him, it "contrasts with everything the government's world of values says about humans." (Rétvári, 2017, quoted in HVG, a weekly print and online daily news outlet). ${ }^{23}$ These were among the arguments used.

If epistemic progress is defined the way the Hungarian government seems to do, and academic freedom is justified via that epistemic progress alone, without reference to the independence of academic research, what is actually protected is quite biased, and far from the openness that those defending the progressivist justification originally had in mind. A progressivist line of defending academic freedom that leaves out reference to critical thinking as a fundamental freedom (a causal independence of the mind) is thus politically, i.e. in practice, quite vulnerable, since then it all depends on the kind of epistemic progress and the values and wellbeing assumed since they determine what matters, i.e. which truths should be sought for. ${ }^{24}$

Thus, the moment the value of independence, and thus dissent, is left out in an account of academic freedom, the latter will go with the former, as part of the decisions for the kind of social and epistemic progress that the respective political regime deems to be in their service. Without reference to independence, academic freedom can too easily become a victim of what Dworkin (1998: 189) has called "cultures of conformity", characterized by a "totalitarian epistemology", in which.

"truth is not collected person by person, in acts of independent conviction, but is embedded in monolithic traditions or the fiats of priesthood or junta or majority vote, and dissent from that truth is treason. That totalitarian epistemology - searingly identified in the finally successful campaign of Orwell's dictator to make his victim believe, through torture, that $2+2=5-i$ s tyranny's most frightening feature."

Contemporary authoritarian regimes (such as Viktor Orbán's “illiberal democracy” in Hungary) do not even need torture to achieve such ends. Cutting funds for public schools, public universities, arts and culture and civil organizations (e.g. NGOs), together with abuse of legal means to regulate media, education, research and civil organizations, simple closure or restructuring of institutions that do not 'fit in', abuse of social media and

\footnotetext{
${ }^{23}$ In Hungarian: "A szak tartalma szemben áll mindazzal, amit a kormány értékvilága az emberrôl vall." (translation László Kőszeghy).

24 I am not arguing from the perspective of value-freedom. I rather argue that it is important to always include one specific epistemic and social value: independence of thought.
} 
(last but not least) simple, old-fashioned propaganda and corruption seem to be sufficient, to bend (or drive abroad) - first the people, and then the truths.

Only if the concept of academic freedom entails a reference to the causal independence of the mind that allows for knowledge production and preservation to happen in an adequate manner can one protect the academic world even in a case in which a government unduly tries to limit academic freedom in the name of progress. Such an augmented concept of academic freedom allows for a non-progressivist defense of it so that old truths are protected too. Since the reference to independence entails a reference to the pluralities and diversities usually cherished under the banner of a social democracy it also allows for an intrinsic connection between the argument from democracy and the argument from truth, a connection between the ethics and the epistemology of the kind of knowledge production and preservation that we still call 'academic' - and for a reason, since it stands for a critical and simultaneously constructive and disciplined freedom, a freedom that is at the core of creativity, academic freedom and an open, just and democratic society.

Acknowledgements I owe Philip Kitcher and Alexander Reutlinger a debt of gratitude for the many inspiring discussions related to the topic of the paper. Many thanks to Alexander Bird for organizing and inviting me to the 2019 British Society of Aesthetics Conference "Creativity Across the Arts and Sciences" in Bristol (Apr 16-17), where I presented the very first rough draft of this contribution. Deep thanks also to the audience at that event, two anonymous referees and the editors of this topical collection for very valuable and engaging feedback. László Kőszeghy deserves credit and thanks for his help and feedback with respect to the case from Hungary, for the translation of the Hungarian sources and for copy-editing assistance. My research is funded by CEU's Research Excellence Fund.

Funding CEU Research Excellence Fund.

\section{Declarations}

Ethical approval Since no ethical issues are directly dealt with, no ethical approval was necessary.

Informed consent Not applicable since no study participants who could give consent were involved.

Open Access This article is licensed under a Creative Commons Attribution 4.0 International License, which permits use, sharing, adaptation, distribution and reproduction in any medium or format, as long as you give appropriate credit to the original author(s) and the source, provide a link to the Creative Commons licence, and indicate if changes were made. The images or other third party material in this article are included in the article's Creative Commons licence, unless indicated otherwise in a credit line to the material. If material is not included in the article's Creative Commons licence and your intended use is not permitted by statutory regulation or exceeds the permitted use, you will need to obtain permission directly from the copyright holder. To view a copy of this licence, visit http://creativecommons.org/licenses/ by $/ 4.0 \%$.

\section{References}

Andreescu, L. (2009). Foundations of academic freedom: making new sense of some aging arguments. Studies in Philosophy and Education, 28(6), 499-515.

Barendt, E. M. (2010). Academic Freedom and the Law: A Comparative Study. Hart Publishing. Basalla, G. (1988). The Evolution of Technology. Cambridge University Press.

Boden, M. A. (2004). The Creative Mind: Myths and Mechanism. Routledge. 
Bush, V. (1945). Science: the endless frontier. A Report to the President. United States Government Printing Office.

Dworkin, R. (1998). We need a new interpretation of academic freedom. In L. Menand (Ed.), The Future of Academic Freedom (pp. 187-198). University of Chicago Press.

Elster, J. (2000). Ulysses Unbound Studies in Rationality, Precommitment, and Constraints. Cambridge University Press.

Findlay, A. (1968). A Hundred Years of Chemistry. 3rd ed. London: Duckworth.

Fish, S. (2014). Versions of Academic Freedom: From Professionalism to Revolution. University of Chicago Press.

Gaut, B. (2009). Skill and creativity. In M. Krausz, D. Dutton \& K. Bardsley (Eds.), The idea of creativity. Philosophy of history and culture (pp. 83-104). Brill.

Guston, D. H. (2000). Between Politics and Science. Cambridge University Press.

Kitcher, P. (2004). On the autonomy of the sciences. Philosophy Today, 48(5), 51-57.

Kitcher, P. (2011). Science in a Democratic Society. Prometheus Books.

Kronfeldner, M. (2009). Creativity naturalized. Philosophical Quarterly, 59, 577-592.

Kronfeldner, M. (2011). Darwinian Creativity and Memetics. Routledge.

Kronfeldner, M. (2018). Explaining creativity. In B. Gaut \& M. Kieran (Eds.), Routledge Handbook on Creativity and Philosophy (pp. 213-229). Routledge.

Leiter, B. (2018). Why Academic Freedom? In D. A. Downs \& C. W. Surprenant (Eds.), The Value and Limits of Academic Speech: Philosophical, Political, and Legal Perspectives (pp.31-46). London: Routledge.

Matei, L., \& Iwinska, J. (2018). Diverging Paths? Institutional Autonomy and Academic Freedom in the European Higher Education Area. In A. Curaj (Ed.), European Higher Education Area: The Impact of Past and Future Policies (pp. 345-368). Springer International Publishing.

Mesoudi, A. (2008). Foresight in cultural evolution. Biology and Philosophy, 23(2), 243-255.

Mill, J. S. (1859). On Liberty. J.W. Parker.

Öllinger M., et al. (2013). Cognitive mechanisms of insight: The role of heuristics and representational change in solving the eight-coin problem. Journal of Experimental Psychology: Learning, Memory, and Cognition, 39(3), 931-939.

Oreskes, N., \& Conway, E. M. (2010). Merchants of Doubt: How a Handful of Scientists Obscured the Truth on Issues from Tobacco Smoke to Global Warming. Bloomsbury.

Polanyi, M. (1951). The Logic of Liberty: Reflections and Rejoinders. Routledge.

Post, R. (2006). The structure of academic freedom. In B. Doumani (Ed.), Academic freedom after September 11 (pp. 61-106). Zone Books; Distributed by the MIT Press.

Rétvári, B. (2017). Rétvári: A gender szak szemben áll mindazzal, amit a kormány az emberről vall (The gender program is opposed to everything the government believes about humans). HVG, 7. Mar., 2017. https://hvg.hu/itthon/20170307_Retvari_A_gender_szak_szemben_all_mindazzal_amit_a_kormany_ az_emberrol_vall (last accessed 2/19/2021).

Reutlinger, A. (2021). Objectivity as independence. Episteme, 1-8. https://doi.org/10.1017/epi.2021.5

Roberts, R. M. (1989). Serendipity: Accidental Discoveries in Science. Wiley.

Rudofsky, S. F., \& Wotiz, J. H. (1988). Psychologists and the dream accounts of August Kekulé. Ambix, 35, 31-38.

Serdült, V. (2018). Megszólalt az EMMIa gender szakról: gazdaságilag nem racionális és nincs rá igény (EMMI [Ministry of Human Capacities] on gender courses: they are not economically rational and there is no demand for them), Zoom.hu, 10. Aug. 2018. https://zoom.hu/hir/2018/08/10/megszolaltaz-emmi-a-gender-szakrol-gazdasagilag-nem-racionalis-es-nincs-igeny/ (last accessed 2/19/2021).

Sternberg, R. J., \& Todd I. L. (1999). The concept of creativity: Prospects and paradigms. In R. J. Sternberg (Ed.), Handbook of creativity (pp. 3-15). Cambridge University Press.

Szikra, D. (2018). Ideológia vagy pragmatizmus? Családpolitika az orbáni illiberális demokráciában (Ideology or pragmatism? Family policy in the illiberal democracy of Orbán). http://real.mtak.hu/ 84674/1/Szikra_Dorottya_szelenyi_u.pdf, 227-228. (last accessed 2/19/2021).

Varma, R. (1995). Restructuring Corporate R\&D: from an autonomous to a linkage model. Technology Analysis \& Strategic Management, 7(2), 231-248.

Wilholt, T. (2012). Die Freiheit der Forschung: Begründungen und Begrenzungen. Suhrkamp. 
Ziman, J. (2003). Non-instrumental roles of science. Science and Engineering Ethics, 9(1), 17-27.

Publisher's Note Springer Nature remains neutral with regard to jurisdictional claims in published maps and institutional affiliations. 